\title{
La participación política de los residentes británicos y alemanes en España: el caso de San Miguel de Salinas, Alicante $^{1}$
}

\author{
Raquel Huete ${ }^{2}$ y Alejandro Mantecón ${ }^{3}$
}

\begin{abstract}
RESUMEN
Este estudio se fija en los ciudadanos noreuropeos asentados en la provincia mediterránea de Alicante que tienen un estatus más cercano al de un inmigrante que al de un turista. La importancia que ha cobrado esta corriente inmigratoria ha provocado cambios profundos en muchos municipios. El objetivo es estudiar el papel político de estos ciudadanos en aquellas regiones en las que su presencia es más significativa. El análisis se basa en datos demográficos y de participación en las elecciones municipales de 2011 y en un trabajo cualitativo que ahonda en la comprensión de los procesos informales de participación política. El hecho de que la influencia de los residentes noreuropeos en las instituciones políticas locales no haya crecido al mismo ritmo que su peso demográfico se debe tanto al desinterés de los extranjeros por participar en la vida pública como al interés de las élites políticas por desincentivar dicha participación.
\end{abstract}

Palabras clave: migraciones residenciales, fragmentación social, turismo residencial.

\begin{abstract}
This study focuses on the northern European citizens living in the Alicante province (on Spain's Mediterranean coast), who are more like immigrants than tourists. This migration flow has become so significant that has brought about profound changes in many towns. Our objective is to examine the political role of these citizens in the regions where they are more present. Our analysis is based on demographic data and data on participation in the 2011 local election, as well as on a qualitative approach that delves into the informal processes of political participation. The fact that the influence of northern European residents on local political institutions has not grown at the same rate as their demographic weight is a consequence of both their lack of interest in public affairs and the interest of political elites in deactivating that participation.
\end{abstract}

Key words: residential migrations, social fragmentation, residential tourism.

1 Proyecto GV/2011/037.Dualización socio- espacial de turistas y residentes europeos: implicaciones para las políticas locales. Ayuda para la realización de proyectos de investigación para grupos de investigación emergentes de la Conselleria de Educación. Artículo recibido el 21 de junio de 2011, aceptado el 16 de enero de 2012 y corregido el 24 de enero de 2012.
2 Departamento de Sociología I e Instituto Universitario de Investigaciones Turísticas, Universidad de Alicante (España). E-mail: r.huete@ua.es

3 Departamento de Sociología I e Instituto Universitario de Investigaciones Turísticas, Universidad de Alicante (España). E-mail: alejandro.mantecon@ua.es 
Mientras la dictadura franquista (19391975) atravesaba el ecuador de su triste singladura y los expertos acólitos al régimen debatían el rumbo que debía tomar el país, el endeble tejido empresarial español inició un proceso de especialización alrededor de una industria de la construcción que se orientaba de manera cada vez más decidida hacia un modelo de crecimiento sostenido en la producción de viviendas vinculadas al consumo de ocio; viviendas situadas principalmente en las regiones que mejor se adaptaban a la promoción del turismo de masas basado en la oferta básica de "sol y playa", es decir, en las regiones bañadas por el mar Mediterráneo y, también, en las Islas Canarias (Pack, 2006).

El ocio turístico representa hoy solo una parte, imposible de cuantificar con exactitud, de la industria basada en el binomio construcción-ocio, pues muchas de las viviendas edificadas con la excusa del desarrollo turístico han pasado a ser ocupadas de forma más o menos permanente por ciudadanos noreuropeos que residen en ellas tras su jubilación o durante periodos de tiempo de muy diversa duración por motivos más cercanos al consumo de experiencias de ocio que a las funciones productivas. Así pues, la construcción de viviendas destinadas al uso vacacional se imbricó con el incremento de los flujos de turismo residencial de larga duración y de inmigración no laboral, dando lugar a formas de movilidad humana en las que se confunden los límites entre el turismo y la migración (Huete, 2009; Huete y Mantecón, 2010; O’Reilly, 2003; Rodríguez, 2001; Rodríguez et al., 2005; Salvà, 2002).

La articulación del turismo con el negocio inmobiliario proyecta lo que se ha denominado "la sombra del turismo": procesos que ocultan la escasa competitividad de la economía estrictamente turística, fomentando además la fragmentación social y territorial en las regiones receptoras (González et al., 2009; Otero \& González, 2011). Las situaciones de conflicto sociopolítico protagonizadas por distintos grupos nacionales que tienen su origen en la ocupación y transformación de territorios de potencial uso turístico no son, obviamente, exclusivas del caso español. Dichos conflictos se han extendido por todo el planeta a la par que el desarrollo turístico y residencial; ejemplos ilustrativos se hallan en
Estados Unidos (Tremblay \& O'Reilly, 2004), México (Clausen, 2009), Costa Rica (Janoschka, 2011), Brasil (Cruz, 2009), Tailandia (Howard, 2009), Dubai (Guerrero, 2009), Turquía (Nudrali \& O'Reilly, 2009) o Marruecos (Gil de Arriba, 2011).

Entre los diversos efectos provocados en las provincias mediterráneas españolas por el intenso crecimiento del modelo económico basado en la construcción de viviendas destinadas a servir de soporte a experiencias de consumo de ocio -o, también, a la especulación inmobiliaria (Mazón, 2006)- destaca el surgimiento en multitud de municipios de nuevos asentamientos urbanos distanciados de los núcleos de población tradicionales ${ }^{4}$. La aparición de estos asentamientos tuvo su origen en la franja litoral durante los años sesenta (Nasarre, 1972), pero la presión urbanística que esa franja ha experimentado en las últimas dos décadas ha provocado que a menudo los viejos y los nuevos núcleos acaben por unirse hasta configurar un continuo urbano a lo largo de toda la línea de la costa. La saturación del suelo disponible en la primera línea ha dado lugar a que los promotores inmobiliarios, en connivencia con las autoridades políticas municipales, hayan repetido (hasta que el mercado de la vivienda se congelara en 2008 tras el estaIlido de la burbuja inmobiliaria) las mismas dinámicas de producción urbana en las áreas mediterráneas prelitorales, en las que ahora se aprecia con más nitidez las tendencias a la fragmentación del territorio entre los núcleos poblacionales habitados principalmente por residentes españoles y los nuevos enclaves urbanos en los que los españoles tienen un peso demográfico minoritario. La distancia entre ambos asentamientos alude a la desigual distribución de los grupos sociales y a la ausencia de relación entre esos grupos. Así, la especialización funcional del territorio y las diferencias socioculturales quedan representadas en el espacio. Específicamente, se hace referencia a la proliferación de urbanizaciones ${ }^{5}$ separadas varios kilómetros

\footnotetext{
4 España está organizada jurídico-administrativamente en 17 Comunidades Autónomas que integran a 50 provincias, y estas, a su vez, a un total de 8.111 municipios.

5 El término "urbanización" tiene dos acepciones: (1)
} 
de los núcleos tradicionales (aunque pertenecientes al mismo término municipal) en las que reside una cantidad atípica de ciudadanos noreuropeos, sobre todo británicos y alemanes (en cuyas ferias inmobiliarias es habitual que se vendan directamente la práctica totalidad de las viviendas que integran la nueva urbanización), lo que produce la sensación en el visitante ocasional de hallarse ante una sociedad paralela (Huete y Mantecón, 2011; Mantecón et al., 2009). La reflexión que plantean González et al. (2009: 85), a propósito del significado que adquieren estos espacios en destinos montañosos de Argentina, se adapta bien a lo que sucede en docenas de municipios ubicados en el prelitoral de las regiones mediterráneas españolas: "son lugares que conforman sistemas morfológica y funcionalmente aislados; lugares sin historia [...] Son también lugares de nuevos conflictos y nuevas formas de interacciones sociales". No obstante, conviene recalcar que, al contrario de lo que a menudo sucede en las áreas residenciales de Latinoamérica, en las que la urbanización adopta morfológica y simbólicamente el carácter de una fortificación de lujo inaccesible para los moradores locales (Janoschka, 2009), en el sur de España esas urbanizaciones corren el riesgo de degenerar en espacios con unas pobres infraestructuras urbanas y de ocio, en los que sus residentes, noreuropeos en su mayoría, experimentan dificultades relacionadas con los cortes en el suministro de electricidad y agua potable, el acceso a medios de transporte público, o el miedo a ser asaltados, pues es habitual que en las urbanizaciones no exista una presencia policial que disuada a posibles delincuentes atraídos por vecindarios en los que saben que muchas viviendas permanecen vacías durante largos periodos (Huete y Mantecón, 2011).

La atención de este estudio se fija en aquellos ciudadanos británicos y alemanes

el proceso de transformación de un terreno en un núcleo de población construyendo calles y dotándolo de las instalaciones y servicios necesarios; y (2) un núcleo residencial de población, generalmente situado a las afueras de una ciudad, formado por construcciones de características semejantes y equipado con servicios propios. asentados en la provincia mediterránea de Alicante que tienen un estatus más cercano al de un inmigrante que al de un turista. Se trata de personas cuya situación podría englobarse con términos como "amenity migrants" (Moss, 2006) o "lifestyle migrants" (Benson \& O'Reilly, 2009). Dichas expresiones se han propuesto en los últimos años desde el ámbito académico anglosajón para referirse a estas tendencias postmodernas de movilidad humana (Hidalgo \& Zunino, 2011; Otero \& González, 2011). En definitiva, se hace referencia aquí a individuos cuya presencia en España no viene motivada tanto por el deseo de interrumpir temporalmente su vida cotidiana en el país emisor como por el anhelo de redefinir su cotidianidad en torno a un estilo de vida en el que la esfera del ocio se sitúa en el centro de los intereses y comportamientos diarios.

La importancia que ha cobrado la presencia de esta corriente inmigratoria en la España mediterránea ha alterado las dinámicas económicas, socioculturales, urbanas y ambientales de muchos municipios. En las siguientes líneas se analizan las implicaciones políticas. El objetivo concreto de este trabajo es estudiar el papel político que estos ciudadanos desempeñan en aquellas regiones españolas en las que su presencia es más significativa. El análisis propuesto en las siguientes páginas, tras la presentación del caso de estudio, se ordena en dos partes. En la primera se realiza una aproximación cuantitativa acerca de la presencia de la población a la que se ha hecho referencia en la política formal de la provincia de Alicante. Esta fase del trabajo se sostiene en los resultados de las elecciones municipales celebradas el domingo 22 de mayo de 2011. En la segunda parte, y tras comprobar la dimensión real de la participación política formal de estos ciudadanos, el estudio se adentra en la comprensión, desde una perspectiva cualitativa, de los procesos informales de participación política, es decir, en las estrategias que estos ciudadanos emplean -y en las dificultades que encuentran- para organizar sus intereses en el ámbito local en torno a acciones colectivas con sentido. 


\section{Metodología}

Se explica ahora la forma de proceder en la etapa correspondiente al trabajo cualitativo. En primer lugar se seleccionó un municipio tipológicamente representativo, de utilidad para profundizar en el objetivo de la investigación. Ese municipio, localizado en la provincia de Alicante fue San Miguel de Salinas (en el siguiente apartado se justifica su selección). En concreto, se organizaron dos grupos de discusión en los que participaron 16 vecinos: 12 británicos (ocho hombres y cuatro mujeres) y cuatro alemanes (un hombre y tres mujeres) de edades comprendidas entre los 50 y los 84 años. Las sesiones grupales se realizaron en las instalaciones puestas a disposición de los investigadores por una asociación de vecinos local en octubre de 2010. Finalmente, entre enero y febrero de 2011 se realizaron 20 entrevistas en profundidad a vecinos noreuropeos residentes del municipio: 15 británicos (siente hombres y ocho mujeres) y cinco alemanes (tres hombres y dos mujeres) de edades comprendidas entre los 56 y los 80 años. El guión de estas entrevistas era semiestructurado, en torno a seis subtemas que primero habían surgido y se habían tratado de forma menos sistemática en los dos grupos de discusión: a) las razones del traslado al municipio, b) la valoración de la vida cotidiana en San Miguel de Salinas, c) las repercusiones de la crisis económica, d) la interacción con los residentes españoles, e) la experiencia con el sistema sanitario español, y f) el papel de los inmigrantes residenciales en la política local. En este trabajo se hará referencia específicamente a las cuestiones políticas. Las 20 entrevistas se Ilevaron a cabo en las instalaciones de la misma asociación. El tamaño de esta segunda muestra se decidió, siguiendo el criterio básico en la investigación cualitativa, cuando se alcanzó el punto de saturación discursiva de la información recogida. Todas las personas que participaron en los grupos de discusión y en las entrevistas en profundidad eran ciudadanos que poseían una vivienda en propiedad en San Miguel de Salinas -algunos conservan una vivienda en su país de origen y otros no- y pasan en el municipio más de seis meses al año, por lo que su situación residencial tiene más semejanzas con la de un migrante que con la de un turista. Aunque la lógica residencial de muchas de estas personas ha sido un tanto irregular, todos reconocieron vivir en España desde hace entre tres y quince años. Asimismo, todos admitieron que las cuestiones profesionales no habían sido las que habían motivado su traslado, sino, más bien, otros aspectos relacionados con la búsqueda de una mejora de la calidad de vida al margen de los aspectos laborales. En este sentido, se apunta que la mayoría se habían trasladado tras la jubilación (en varios casos jubilaciones anticipadas) o en compañía de su cónyuge jubilado (un estudio detallado sobre las motivaciones de los noreuropeos para desplazarse a las regiones mediterráneas españolas puede consultarse en Huete, 2009).

\section{El caso de estudio}

El Instituto Nacional de Estadística de España indica que el $15 \%$ de las 1.921 .988 personas que en 2010 residen en la provincia de Alicante son originarias de otros Estados de la Unión Europea (UE). Específicamente, las estadísticas oficiales informan que en la provincia de Alicante habitan el 34\% (130.302) del total de los británicos registrados en España y el 19\% (36.543) de los alemanes. Es importante subrayar que se trata de una población envejecida: en la provincia de Alicante representan al $25 \%$ de los ciudadanos mayores de 65 años. Al respecto, se apunta que 44.692 del total de los británicos registrados en esta provincia son mayores de 65 años y 17.587 en el caso de los alemanes. Además, estudios sociológicos llevados a cabo recientemente desde el ámbito universitario aclaran que, en realidad, la gran mayoría de estas personas están jubiladas o en un momento de su vida próximo a la jubilación (Huete, 2009; Mantecón et al., 2009).

En 19 municipios de esta provincia reside más población procedente de otros Estados de la UE que nacida en España. Por lo tanto, no debe extrañar el hecho de que durante la pasada década esta fuera la provincia española preferida por los ciudadanos extranjeros para adquirir una vivienda. El intenso crecimiento que ha experimentado el asentamiento de ciudadanos noreuropeos en esta región se ilustra con el caso del municipio de San Miguel Salinas, localizado en un área prelitoral del sur de la provincia, a treinta kilómetros del mar Mediterráneo (ver Figura № 1). 
Figura $\mathrm{N}^{0} 1$

Mapa de San Miguel de Salinas con las urbanizaciones y el centro urbano

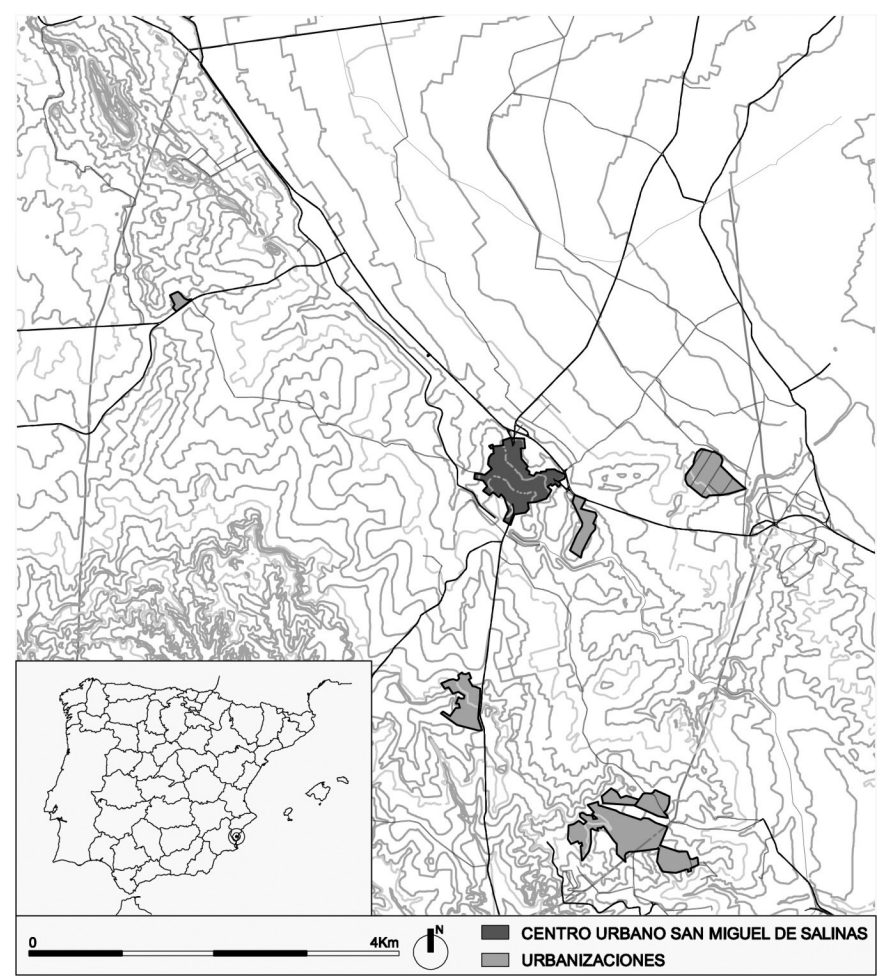

Fuente: Elaboración propia a partir de cartografía oficial.

Las estadísticas producidas por el Padrón Municipal de Habitantes durante los últimos quince años advierten de una evolución demográfica que Ilama la atención. En 1995, en San Miguel de Salinas se hallaban empadronados 3.521 habitantes, de ellos 686 (el 19,5\%) eran europeos no españoles. En el año 2000 se hallaban empadronados 3.893 habitantes, de ellos 982 (el 25,2\%) eran europeos no españoles, siendo las dos nacionalidades de extranjeros con una presencia mayor la británica (493 habitantes que representaban al 12,7\% del total de empadronados) y la alemana (332 habitantes que representaban al 8,5\% del total de empadronados). En el año 2005, el Padrón Municipal registraba a 6.620 habitantes, de ellos 3.547 $(53,6 \%)$ eran europeos no españoles, y las dos nacionalidades de extranjeros con una presencia mayor eran la británica (2.262 habitantes que representaban al $34,2 \%$ del total de empadronados) y la alemana (631 habitantes que representaban al 9,5\% del total de empadronados). En el año 2010 se hallaban registrados 8.057 habitantes, de ellos 4.857 (60,3\%) eran europeos no españoles, siendo las dos nacionalidades de extranjeros más numerosas la británica (3.310 habitantes que representaban al $41,1 \%$ del total de empadronados) y la alemana (693 habitantes que representaban al 8,6\% del total de empadronados). En estos quince años el número de residentes españoles prácticamente no ha variado, pasando de 2.795 en 1995 (79,4\% del total de la población registrada) a 2.871 en 2010 (35,6\% del total). Una encuesta reciente (Huete y AVSM, 2010) revela que el $83,5 \%$ de los británicos y alemanes que reside en este municipio lo hace en urbanizaciones localizadas en las periferias del término municipal (ver el mapa), mientras que un 16,5\% vive en el núcleo urbano tradicional. Por lo tanto, puede advertirse que el crecimiento demográfico del municipio se ha imbricado con la expansión 
de las urbanizaciones periféricas construidas en los últimos años alrededor del centro urbano tradicional.

\section{El peso electoral}

En el Cuadro № 1 se aprecia cómo entre las diez nacionalidades que aglutinan al mayor flujo de ciudadanos inmigrantes en España -registrados en 2010- los británicos y los alemanes se encuentran en cuarto y séptimo lugar respectivamente. Tal y como ya se ha explicado, estudios sociológicos recientes (Huete, 2009) aclaran que la mayor parte de las personas que proceden de estos dos países conforman un flujo inmigratorio diferente al de las otras ocho nacionalidades apuntadas. La razón de esa diferenciación tiene que ver esencialmente con las motivaciones principales que orientan las actitudes y comportamientos de estos ciudadanos: los británicos y alemanes se hallan más próximos a valores ligados a la esfera del ocio y en los otros casos se encuentran más cercanos a intereses vinculados a la esfera laboral/ productiva. Si descendemos del nivel estatal al nivel autonómico (Comunidad Valenciana), se percibe cómo el contingente británico pasa de la cuarta a la primera posición y la población alemana de la séptima a la quinta en la lista de las nacionalidades que agrupan a un mayor número de extranjeros. Al descender al nivel provincial (provincia de Alicante), se observa cómo la población británica se mantiene en primera posición entre los inmigrantes extranjeros, aunque su peso relativo aumenta del 2,8\% de la comunidad autónoma hasta un $6,8 \%$, y la población alemana pasa de la quinta posición que ocupaba en el ranking de la comunidad autónoma a la segunda posición, siendo así la británica y la alemana las dos nacionalidades que agrupan a un mayor número de extranjeros registrados. La situación se vuelve especialmente Ilamativa cuando descendemos al contexto municipal de San Miguel de Salinas: los británicos y los alemanes reúnen al 49,7\% de la población registrada, al tiempo que las nacionalidades que agrupan a los flujos de inmigración económica convencional pierden peso relativo.

\section{Cuadro $\mathrm{N}^{\circ} 1$}

Las diez principales nacionalidades en los distintos niveles de organización territorial

\begin{tabular}{|c|c|c|c|c|c|c|c|c|}
\hline & España & $\begin{array}{c}\text { Porcentaje } \\
\text { población } \\
\text { Total }\end{array}$ & $\begin{array}{l}\text { Comunidad } \\
\text { Valenciana }\end{array}$ & $\begin{array}{c}\text { Porcentaje } \\
\text { de } \\
\text { población } \\
\text { Total } \\
\end{array}$ & $\begin{array}{l}\text { Provincia } \\
\text { de } \\
\text { Alicante }\end{array}$ & $\begin{array}{c}\text { Porcentaje } \\
\text { población } \\
\text { Total }\end{array}$ & $\begin{array}{c}\text { San } \\
\text { Miguel } \\
\text { de } \\
\text { Salinas } \\
\end{array}$ & $\begin{array}{c}\text { Porcentaje } \\
\text { de } \\
\text { población } \\
\text { Total } \\
\end{array}$ \\
\hline $\begin{array}{l}\text { Total } \\
\text { población }\end{array}$ & 47.021 .031 & 100 & 5.111 .706 & 100 & 1.926 .285 & 100 & 8.057 & 100 \\
\hline $\begin{array}{l}\text { Total } \\
\text { españoles }\end{array}$ & 41.273 .297 & 87,8 & 4.217 .947 & 82,5 & 1.459 .186 & 75,8 & 2.871 & 35,6 \\
\hline $\begin{array}{l}\text { Total } \\
\text { extranjeros }\end{array}$ & 5.747 .734 & 12,2 & 893.759 & 17,5 & 467.099 & 24,2 & 5.186 & 64,4 \\
\hline Rumania & 831.235 & 1,8 & 141.391 & 2,8 & 32.683 & 1,7 & 49 & 0,6 \\
\hline Marruecos & 754.080 & 1,6 & 75.702 & 1,5 & 34.267 & 1,8 & 70 & 0,9 \\
\hline Ecuador & 399.586 & 0,8 & 48.314 & 0,9 & 21.683 & 1,1 & 70 & 0,9 \\
\hline $\begin{array}{l}\text { Reino } \\
\text { Unido }\end{array}$ & 387.677 & 0,8 & 144.078 & 2,8 & 130.302 & 6,8 & 3.310 & 41,1 \\
\hline Colombia & 292.641 & 0,6 & 43.043 & 0,8 & 19.278 & 1,0 & 21 & 0,3 \\
\hline Bolivia & 213.169 & 0,5 & 25.437 & 0,5 & 5.191 & 0,3 & 6 & 0,1 \\
\hline Alemania & 195.824 & 0,4 & 43.249 & 0,8 & 36.543 & 1,9 & 693 & 8,6 \\
\hline Italia* & 184.277 & 0,4 & 24.811 & 0,5 & 10.687 & 0,6 & 15 & 0,2 \\
\hline Bulgaria & 169.552 & 0,4 & 37.337 & 0,7 & 12.687 & 0,7 & 99 & 1,2 \\
\hline China & 158.244 & 0,3 & 17.151 & 0,3 & 7.279 & 0,4 & 43 & 0,5 \\
\hline
\end{tabular}

* Una parte muy significativa del contingente de inmigrantes de nacionalidad italiana son nacidos en Argentina con doble nacionalidad.

Fuente: Elaboración propia a partir de Instituto Nacional de Estadística (INE). Revisión del Padrón municipal 2010. 
El incremento de los flujos de inmigración residencial de noreuropeos procedentes de la UE y su derecho a votar en las elecciones municipales puede determinar el equilibrio de fuerzas políticas en muchos ayuntamientos. De hecho, tras las elecciones municipales de 2007 pudo apreciarse cómo las asociaciones de europeos residentes se organizaron políticamente y consiguieron ganar tres docenas de concejalías en ayuntamientos de la provincia de Alicante, que fueron ocupadas por ciudadanos de la UE no españoles (Janoschka, 2010). Al mismo tiempo, 25 municipios pasaron a contar con un concejal dedicado exclusivamente a tratar con las cuestiones que afectan a los residentes extranjeros.

El censo electoral de las elecciones locales está compuesto por el censo de electores españoles (CER) y por el censo de electores extranjeros residentes en España con derecho a voto (CERE), que incluía para las elecciones locales del 22 de mayo de 2011 a los nacionales de otros países de la Unión Europea -siempre que hubieran manifestado su intención de votar con anterioridad al 1 de febrero de 2011 en la Oficina del Censo Electoral- y a los nacionales de países con acuerdos políticos que les reconocen el derecho de sufragio en esas elecciones en los términos de un tratado vigente entre España y otros Estados: Noruega, Ecuador, Nueva Zelanda, Colombia, Chile, Perú, Paraguay, Islandia, Bolivia y Cabo Verde. La lista (en orden alfabético) de los electores extranjeros residentes en España y en la provincia de Alicante se presenta en el Cuadro $\mathrm{N}^{\circ} 2$. Puede apreciarse cómo la británica y la alemana son la segunda y la tercera nacionalidad que aglutinan a un mayor número de electores extranjeros registrados en España, si bien, para el caso de la provincia de Alicante esas dos nacionalidades ocupan los dos primeros lugares. No deja de resultar Ilamativo que el $21,4 \%$ de los electores alemanes residentes en todo el país se hallen en la provincia de Alicante y que ese porcentaje ascienda al $38,2 \%$ en el caso de los británicos.

Para el total de la Comunidad Valenciana, en 2011 los electores británicos inscritos en el censo electoral han representado el $47,22 \%$ del electorado europeo y los alemanes el 12,96\%. Ambas nacionalidades han ganado peso con respecto a los electo- res extranjeros en las anteriores elecciones municipales de 2007 (40,65\% y 11,92\%, respectivamente), pero lo perdieron si se tienen en cuenta los datos de las elecciones de 2003 previos a las ampliaciones de la Unión Europea (UE25 y UE27), gracias a las cuales los rumanos, búlgaros y polacos pasaron a convertirse en electores europeos.

Según el Padrón Municipal de Habitantes de 2011, había en San Miguel de Salinas 2.322 españoles y 4.674 extranjeros de los países con derecho a voto en las elecciones locales de más de 18 años (edad a partir de la cual se puede ejercer el derecho al voto en España). En las recientes elecciones locales celebradas el 22 de mayo de 2011 votaron en San Miguel de Salinas 2.169 electores sobre un censo de 3.497 personas. El número de censados significa que manifestaron su intención de votar (mediante su inscripción previa en la Oficina del Censo Electoral) 1.175 extranjeros, el $25 \%$ de los extranjeros empadronados con derecho a voto. Los datos de inscripción en el censo electoral en este municipio son algo inferiores a los datos disponibles por nacionalidades para el conjunto de la Comunidad Valenciana, donde el $30 \%$ de los británicos y el $27 \%$ de los alemanes empadronados están inscritos en el CERE. Además, la situación en las anteriores elecciones locales, celebradas en 2007, fue muy similar en cuanto al número de electores extranjeros y a su peso en el conjunto del electorado de San Miguel de Salinas. En definitiva, mientras que la población extranjera representa al $64,4 \%$ de la población local (solamente contando a los británicos y alemanes ya se agrupa a casi la mitad de la población registrada en San Miguel de Salinas) su participación electoral real dista mucho de su participación potencial (INE, 2011).

En el municipio de San Miguel de Salinas, se presentaron a las elecciones locales de 2011 cuatro formaciones políticas: el Partido Popular (PP), el Partido Socialista Obrero Español (PSOE), Esquerra Unida del País Valencià (EUPV) y el Centro Democrático Liberal (CDL). En la sexta posición de la candidatura de EUPV y en la novena de la del PSOE se encontraban los únicos candidatos con nombre extranjero según las listas oficiales. El PP y el CDL no incluían extranjeros en sus listas. En la anterior corporación municipal 
tampoco había extranjeros entre los concejales ni del gobierno local ni de la oposición. Finalmente, las elecciones del 22 de mayo de 2011 acabaron en San Miguel de Salinas con el triunfo del PP $(57,5 \%$ de los votos, que se corresponden con 8 concejales), seguido por el PSOE $(25,7 \%$ de los votos, que equivalen a 3 concejales), EUPV (14,1\% de los votos, que posibilitan 2 concejales) y el CDL $(2,7 \%$ de los votos, que no permiten ningún concejal).

Cuadro $\mathrm{N}^{\circ} 2$

Número de electores extranjeros residentes en España y en la provincia de Alicante, por nacionalidad

\begin{tabular}{|l|r|r|}
\hline País de procedencia & España & $\begin{array}{c}\text { Provincia } \\
\text { de } \\
\text { Alicante }\end{array}$ \\
\hline Alemania & 47.483 & 10.142 \\
Austria & 2.209 & 271 \\
Bélgica & 9.159 & 2.640 \\
Bolivia & 5.042 & 166 \\
Bulgaria & 19.437 & 1.496 \\
Cabo Verde & 22 & 0 \\
Chile & 1.249 & 52 \\
Chipre & 23 & 1 \\
Colombia & 12.632 & 1.147 \\
Dinamarca & 3.371 & 457 \\
Ecuador & 25.668 & 1.821 \\
Eslovenia & 142 & 3 \\
Estonia & 145 & 15 \\
Finlandia & 2.758 & 375 \\
Francia & 33.203 & 3.728 \\
Grecia & 831 & 56 \\
Hungría & 784 & 100 \\
Irlanda & 4.169 & 865 \\
\hline
\end{tabular}

\begin{tabular}{|l|r|r|}
\hline País de procedencia & España & $\begin{array}{c}\text { Provincia } \\
\text { de } \\
\text { Alicante }\end{array}$ \\
\hline Islandia & 28 & 2 \\
Italia & 40.663 & 2.483 \\
Letonia & 374 & 49 \\
Lituania & 1.731 & 191 \\
Luxemburgo & 176 & 34 \\
Malta & 36 & 1 \\
Noruega & 829 & 434 \\
Nueva Zelanda & 33 & 1 \\
Países Bajos & 14.790 & 5.352 \\
Paraguay & 645 & 29 \\
Perú & 5.897 & 85 \\
Polonia & 7.823 & 422 \\
Portugal & 21.582 & 419 \\
Reino Unido & 103.797 & 39.608 \\
República Checa & 971 & 96 \\
República Eslovaca & 851 & 109 \\
Rumanía & 105.825 & 4.522 \\
Suecia & 5.438 & 1.333 \\
\hline
\end{tabular}

Fuente: Instituto Nacional de Estadísticas. Oficina del Censo Electoral. Elecciones locales de mayo de 2011

\section{Aproximación cualitativa a las formas de participación política}

El peso electoral de los noreuropeos, la aparición de organizaciones de voluntarios que, en coordinación con la policía, se de- dican a hacer vigilancia nocturna de sus vecindarios, el surgimiento de grupos ecologistas integrados principalmente por residentes extranjeros contrarios a la especulación inmobiliaria, entre otros, reflejan una nueva realidad sociopolítica. La acción colectiva de los británicos y alemanes en el sur de España es interpretada por Michael Janoschka (2010) 
como la plasmación del deseo de estos segmentos de población por configurar un agente social con influencia real sobre las instituciones políticas desde las que se gobierna su nuevo, y en ocasiones solo esporádico, lugar de residencia. Estas nuevas estructuras políticas querrían acabar con la imagen que repetitivamente ha tipificado a los inmigrantes noreuropeos estrictamente como consumidores sin intereses políticos ni problemas graves en la sociedad española. Para este investigador la participación política de los extranjeros residentes que proceden de la UE se ha canalizado hasta el momento de cuatro maneras diferentes: 1) mediante su captación por los partidos españoles con el fin de "atrapar" votos de este nuevo mercado electoral; 2) aprovechando el acceso a concejalías para influir directamente en políticas concretas que contribuyan a la modernización de la sociedad local; 3 ) poniendo de manifiesto conflictos culturales (sociolingüísticos e identitarios) que pueden derivar en procesos tanto integradores como excluyentes; y 4) a través de la creación de nuevas formaciones políticas que obligan a redefinir el sistema de poderes preexistente.

El argumento que se presenta a continuación es el resultado del análisis de la información recopilada a través de la aplicación de los grupos de discusión y las entrevistas en profundidad realizados $y$, en definitiva, tiene como hilo conductor la comprensión de los mecanismos mediante los que se articula la participación política informal de los noreuropeos residentes en San Miguel de Salinas, así como de los aspectos que facilitan o entorpecen esa participación.

Los discursos producidos por los entrevistados ofrecen una visión claramente negativa de la situación política local. Las críticas hacia la gestión llevada a cabo por las autoridades políticas municipales son expresadas constantemente. La mayor parte de los entrevistados no percibe que las autoridades locales tengan un auténtico interés por desarrollar políticas de integración ni por resolver los problemas de infraestructuras que se padecen en las urbanizaciones, donde la población noreuropea tiene un peso demográfico mayoritario. Sin embargo, al contrario de lo que ha ocurrido en otros municipios de la misma provincia, en San Miguel de Salinas los re- sidentes noreuropeos no han desarrollado ninguna de las dos estrategias más habituales: la organización de partidos políticos propios o la integración en los partidos políticos españoles ya existentes. La razón apuntada para no emprender la primera estrategia es clara: prácticamente todos los entrevistados se manifestaron en contra de los partidos formados por personas de una misma nacionalidad. El sentir de la mayoría de los entrevistados puede apreciarse en el razonamiento expuesto por un entrevistado alemán que consideraba la formación de esos partidos en otros municipios cercanos más como una protesta y una comprensible expresión del hartazgo de los residentes noreuropeos respecto a las autoridades políticas españolas que, salvo excepciones, como una voluntad por contribuir de forma constructiva a la solución conjunta de los problemas. En última instancia, y en opinión de casi todos los entrevistados, esas agrupaciones políticas agudizarían los procesos de separación y fragmentación social. La razón señalada para no incorporarse a los partidos políticos españoles (opción reconocida por la mayoría como más realista y deseable) encuentra su explicación en que todos los entrevistados reconocieron la existencia de un déficit en la calidad de la democracia local. Al respecto, se apuntó que los constantes escándalos sobre casos de corrupción y clientelismo producían una atmósfera poco propicia para animarse a participar en el sistema político municipal. En su lugar, los residentes noreuropeos más interesados han optado por integrarse en diversas asociaciones vecinales, lo que también podría interpretarse como un tipo de acción política informal y, quizá, añadirse como una quinta estrategia a las cuatro apuntadas por Janoschka antes citadas.

Es precisamente en el seno de las asociaciones vecinales que reúnen a residentes extranjeros y españoles en donde se reconocen las experiencias de integración más positivas. La identificación de la actividad asociativa al margen de las estructuras políticas formales como una forma de participación política viable y más atractiva para los noreuropeos se presenta en el caso de San Miguel de Salinas como la opción más realista para aquellos ciudadanos noreuropeos que tienen un mayor interés por participar en la vida social española y por, en la medida de lo posible, 
influir en ella. Las razones para encauzar sus inquietudes a través del asociacionismo tienen que ver esencialmente con la necesidad de eliminar una situación de aislamiento respecto a la sociedad española. Esa situación se ve agudizada por el desconocimiento mutuo de los idiomas respectivos, el distanciamiento geográfico motivado por la ubicación periférica de las urbanizaciones (en las que apenas viven españoles) y el desinterés que perciben en las autoridades municipales por comprender y abordar los problemas que experimentan los residentes en esas urbanizaciones.

El espíritu asociacionista típicamente anglosajón ha cristalizado en la provincia de Alicante con la configuración de cientos de asociaciones fundadas por ciudadanos extranjeros procedentes de otros países de la $U E$, generando un tipo de tejido social infrecuente en un país en el que el derecho a la libre asociación estuvo prohibido durante los casi cuarenta años que duró la dictadura franquista. Simó et al. (2005) explican cómo la mayoría de esas asociaciones están integradas por ciudadanos extranjeros que, en ocasiones puntuales, acaban por reforzar la segregación y la división entre los españoles y los extranjeros de la UE. Pero también hay experiencias muy positivas de asociaciones que incluyen a ciudadanos de diversas nacionalidades, también españoles. Así, estas asociaciones se han convertido en espacios lúdicos, de ayuda $y$, también, de conocimiento mutuo, en los que, como en el caso de la Asociación de Vecinos San Miguel Arcángel (de San Miguel de Salinas), se reúnen ciudadanos españoles con otros británicos, alemanes y de otras nacionalidades con el objetivo de organizar excursiones, resolver problemas cotidianos o realizar actividades orientadas a mejorar el conocimiento de los idiomas respectivos. A través del trabajo cualitativo también se ha comprobado cómo los intentos que la asociación citada ha emprendido para articular y trasladar demandas colectivas desde el ámbito social informal hacia el territorio de la política formal se ha topado con el rechazo de aquellas personas que actualmente gestionan la política municipal formal. Sobre esta cuestión, se aprecia la puesta en práctica de diversos mecanismos de control social destinados a impedir que estas nuevas estructuras sociopolíticas influyan en los procesos de toma de decisión: por ejemplo, mediante acciones bastante burdas como el corte del suministro de agua al local de la asociación o intentando deslegitimar sus objetivos en periódicos locales destinados a la población extranjera. También se han desplegado estrategias más sutiles, como las denunciadas por algunos entrevistados a propósito de la existencia en diversas urbanizaciones de portavoces vecinales que actúan como interlocutores entre el ayuntamiento y los residentes de la urbanización, pero que, en la práctica, serían manipulados por las autoridades municipales con el propósito de mantener la atmósfera de apatía sociopolítica que respiran la mayor parte de los extranjeros residentes.

La existencia de la mencionada apatía es percibida por todos los entrevistados, que, a menudo, se reconocían a sí mismos durante las entrevistas como una minoría interesada que convivía junto a otros compatriotas que habían decidido que su traslado a España iba ligado a una desconexión respecto a cualquier tipo de preocupación de carácter social: su vida en San Miguel de Salinas se orientaría exclusivamente por valores hedonistas. Los participantes en la investigación apuntan que, al menos, se puede distinguir entre un grupo minoritario de migrantes residenciales implicados informalmente en la política municipal y en la sociedad local, que convive junto a un grupo mayoritario de residentes extranjeros imbuidos en una clima de apatía respecto a los problemas que suceden en el contexto en el que discurre sus vidas. El estilo de vida de este segundo grupo, orientado por una actitud más próxima a la de un turista (que desconecta momentáneamente de sus preocupaciones cotidianas) que al de un residente, refuerza la configuración (y la construcción en el imaginario de la sociedad local) de una aparente sociedad paralela al margen de la población española. No obstante, el primer grupo, más interesado en la realidad social de San Miguel de Salinas, ve complicada su voluntad de establecer vínculos a causa tanto de un contexto político municipal que desalienta las iniciativas de participación ciudadana como de un modelo urbano, avalado por esas mismas instituciones políticas, que ha generado una estructura urbana fragmentada en torno a un espacio dual donde puede diferenciarse nítidamente entre el centro urbano tradicional y las urbanizaciones periféricas. 
El desinterés ciudadano hacia las cuestiones relacionadas con la actividad sociopolítica no es una característica excepcional ni de San Miguel de Salinas ni de los residentes noreuropeos, más bien, ha de enmarcarse en escenarios más amplios. No obstante, en el caso español esa pérdida de confianza en la legitimidad de las instituciones se agudiza en la esfera municipal, pues en los últimos treinta años el gobierno estatal ha delegado más competencias urbanísticas a las autoridades locales, concentrándose en ese nivel los delitos de corrupción inmobiliaria y las políticas de planificación del territorio orientadas por principios ajenos a la sostenibilidad ambiental y social. De alguna manera, esta evidencia pone en cuestión las interpretaciones de los investigadores que han visto en la acción de estos grupos sociales procesos informales y positivos que tienden a la formación de una "conciencia" (Schriewer y García, 2005) o de una "identidad" (Janoschka, 2010) europea. Los entrevistados en este trabajo se muestran escépticos sobre este asunto $y$, en cambio, opinan que la voluntad por crear vínculos sociales estrechos entre los españoles y los noreuropeos quedaría circunscrita a segmentos minoritarios de ambas poblaciones.

Aunque en el estudio cualitativo realizado se han encontrado básicamente estas dos pautas entre los extranjeros de la UE: la apatía generalizada y la voluntad minoritaria de establecer relaciones sólidas con la población española, también ha de apuntarse una tercera opción que no aparece reflejada claramente en el trabajo de Janoschka (2010) pero que sí ha sido analizada por Simó et al. (2005). Se trata de un comportamiento, reconocible en otros municipios de esta región, en el que se observan grupos de extranjeros distanciados de las actitudes apáticas y que prefieren articular su acción colectiva al margen de los partidos políticos formales mediante la participación activa en asociaciones constituidas por criterios que poseen algún carácter excluyente (nacionalista, étnico o lingüístico), en las que los ciudadanos españoles tienen una presencia anecdótica. Una estrategia que, debe admitirse, no ha conseguido aglutinar la suficiente masa crítica ni ha sabido encauzar sus esfuerzos para ejercer una influencia real, entre otras cosas porque al limitar la presencia de ciudadanos españoles pierden la posibilidad de estable- cer más fácilmente relaciones con personas que poseen el conocimiento necesario para desenvolverse con agilidad en el complejo sistema burocrático-administrativo de la política española.

\section{Consideraciones finales}

El propósito de este trabajo ha sido analizar las implicaciones políticas de las migraciones residenciales en la región mediterránea española. Principalmente, se ha pretendido comprender el papel que los inmigrantes orientados por la motivación de mejorar su calidad de vida en torno a experiencias de ocio (y no a las laborales) han desempeñado en aquellos lugares en los que tienen una presencia cuantitativamente más relevante.

La principal conclusión a la que se ha llegado es que el aumento del peso demográfico de estos ciudadanos no crece al mismo ritmo que su influencia en las instituciones políticas españolas. Ello se debe, sobre todo, al subregistro de esta población en la Oficina del Censo Electoral, lo que demuestra, entre otras cosas, que los problemas experimentados por los residentes extranjeros que habitan en las urbanizaciones periféricas de los términos municipales no han conseguido transformarse en una voluntad real por participar en el sistema político formal.

A la luz del trabajo expuesto, las posibles interpretaciones sobre este asunto oscilan entre dos explicaciones complementarias: por un lado, aquella que apuntaría a la inexistencia de un verdadero interés por parte de estos ciudadanos por implicarse políticamente en la solución de los problemas que acontecen en su país de acogida y, por otro, el interés de las élites políticas españolas por conservar el monopolio en la gestión local de los municipios. Ambas explicaciones han de ser matizadas. Sobre la cuestión del desinterés de los noreuropeos, el trabajo cualitativo realizado ha advertido de la existencia de al menos dos grupos, uno mayoritario formado por personas apáticas respecto a las cuestiones políticas locales, cuya vida en España pretende guiarse por pautas exclusivamente vinculadas al disfrute del ocio, y otro minoritario, que sí se muestra preocupado por las cuestiones 
sociopolíticas pero que renuncia a participar en el sistema político formal debido a los impedimentos que ese sistema impone, tanto formales como informales, para fomentar la participación de estos ciudadanos. Entonces, la participación social colectiva se canalizaría en el caso de San Miguel de Salinas a través de organizaciones ciudadanas ajenas a las estructuras políticas oficiales.

Todo ello nos advierte de la producción de un modelo social en el que aspectos político-económicos, estrechamente vinculados a un desarrollo urbanístico tendente a la fragmentación, refuerzan las dificultades de interacción social entre las distintas comunidades nacionales residentes en el municipio.

\section{Referencias bibliográficas}

BENSON, M. \& O'REILLY, K. Migration and the search for a better way of life: a critical exploration of lifestyle migration. The Sociological Review, 2009, Vol. 57, № 4, p. 608-625.

CLAUSEN, H.B. La utopía de los estadounidenses en un pueblo mexicano. Un estudio sobre la construcción de una comunidad imaginada. En: CLAUSEN, H.B.; GUSTAFSON, J. y VELÁZQUEZ, M. (Editores). Utopías y globalización. Hermosillo: Colegio de Sonora, 2009, p. 87-109.

CRUZ, R. Los nuevos escenarios del turismo residencial en Brasil: un análisis crítico. En: MAZÓN, T.; HUETE, R. y MANTECÓN, A. (Editores). Turismo, urbanización y estilos de vida. Las nuevas formas de movilidad residencial. Barcelona: Icaria, 2009, p. 161-174.

GIL DE ARRIBA, C. Del turismo hotelero al turismo residencial en Marruecos. Entre el negocio inmobiliario y la recreación de imaginarios socioespaciales. Cuadernos de Turismo, 2011, № 27, p. 471-487.

GONZÁLEZ, R.; OTERO, A.; NAKAYAMA, L. y MARIONI, S. Las movilidades del turismo y las migraciones de amenidad: problemáticas y contradicciones en el desarrollo de centros turísticos de montaña. Revista de Geografía Norte Grande, 2009, № 44, p. 75-92.
GUERRERO, S. Dubai: crisis económica y turismo residencial. En: MAZÓN, T.; HUETE, R. y MANTECÓN, A. (Editores). Turismo, urbanización y estilos de vida. Las nuevas formas de movilidad residencial. Barcelona: Icaria, 2009, p. 221-234.

HIDALGO, R. \& ZUNINO, H. Existential Amenity Migrants in Pucón County, Region IX, La Araucanía, Chile: Reinventing the Self and Innovating Social Life. Documento de trabajo presentado en el 2nd International Workshop: Lifestyle Migration and Residential Tourism. Madrid: CSIC, 23-25 de marzo, 2011.

HOWARD, R. The migration of westerners to Thailand: an unusual flow from developed to developing world. International Migration, 2009, Vol. 47, N², p. 193-225.

HUETE, R. Turistas que llegan para quedarse. Una explicación sociológica sobre la movilidad residencial. Alicante: Publicaciones de la Universidad de Alicante, 2009.

HUETE, R. Y AVSM (ASOCIACIÓN DE VECINOS SAN MIGUEL ARCÁNGEL DE SAN MIGUEL DE SALINAS) Resultados de la encuesta sobre la extensión y naturaleza de la integración de los residentes europeos en la sociedad de San Miguel de Salinas. Alicante: Universidad de Alicante, 2010. Disponible en Internet: http://hdl.handle.net/10045/14679.

HUETE, R. y MANTECÓN, A. Más allá del turismo: movilidad residencial europea y nuevos núcleos urbanos. Boletín de la Asociación de Geógrafos Españoles, 2011, № 56, p. 111-128.

HUETE, R. y MANTECÓN, A. Los límites entre el turismo y la migración residencial. Una tipología. Papers. Revista de Sociología, 2010, Vol. 95, N³, p. 781-801.

INE (INSTITUTO NACIONAL DE ESTADÍSTICA) Procesos electorales. 2011. Disponible en Internet: http://www.ine.es

JANOSCHKA, M. The Contested Spaces of Lifestyle Mobilities: Regime Analysis as a Tool to Study Political Claims in Latin American Retirement Destinations. Die Erde, 2009, Vol. $140, N^{\circ} 3$, p. 251-274. 
JANOSCHKA, M. Prácticas de ciudadanía europea. El uso estratégico de las identidades en la participación política de los inmigrantes comunitarios. Arbor, 2010, Vol. CLXXXVI, Nº 744, p. 706-719.

JANOSCHKA, M. Imaginarios del turismo residencial en Costa Rica. Negociaciones de pertenencia y apropiación simbólica de espacios y lugares: una relación conflictiva. En: MAZÓN, T.; HUETE, R. y MANTECÓN, A. (Editores). Construir una nueva vida. Los espacios del turismo y la migración residencial. Santander: Milrazones, 2011, p. 81-102.

MANTECÓN, A.; HUETE, R. y MAZÓN, T. Las urbanizaciones 'europeas'. Una investigación sobre las nuevas sociedades duales en el Mediterráneo. Scripta Nova. Revista Electrónica de Geografía y Ciencias Sociales, 2009, Vol. XIII, $N^{\circ}$ 301. Disponible en Internet: http://www.ub.es/geocrit/sn/sn-301.htm

MAZÓN, T. El turismo litoral mediterráneo ipolíticas turísticas o desarrollo inmobiliario? En: RODRÍGUEZ, J.A. (Editor). Sociología para el futuro. Barcelona: Icaria, 2006, p. 301-310.

MOSS, L. The amenity migrants. Seeking and sustaining mountains and their cultures. Trowbridge: Cromwell Press, 2006.

NASARRE, R. Las urbanizaciones particulares. La Ley del Suelo ante el fenómeno turístico. Madrid: Montecorvo, 1972.

NUDRALI, O. \& O'REILLY, K. Taking the risk: the British in Didim, Turkey. In: BENSON, M. \& O'REILLY, K. (Editors). Lifestyle Migration. Expectations, Aspirations and Experiences. Farnham: Ashgate, 2009, p. 137-152.

O'REILLY, K. When is a tourist? The articulation of tourism and migration in Spain's Costa del Sol. Tourist Studies, 2003, Vol. 3, $N^{\circ} 3$, p. 301-317.
OTERO, A. \& GONZÁLEZ, R. The role of the State facing amenity/ lifestyle mobility processes in Argentina. Documento de trabajo presentado en el 2nd International Workshop: Lifestyle Migration and Residential Tourism. Madrid: CSIC, 23-25 de marzo, 2011.

PACK, S. Tourism and Dictatorship. Europe's Peaceful Invasion of Franco's Spain. Gordonsville: Palgrave, 2006.

RODRÍGUEZ, V. Tourism as a recruiting post for retirement migration. Tourism Geographies, 2001, Vol. 3, № 1, p. 52-63.

RODRÍGUEZ, V.; CASADO, M.A. y HUBER, A. (Editores). La migración de europeos retirados en España. Madrid: CSIC, 2005.

SALVÀ, P. Foreign Immigration and Tourism Development in Spain's Balearic Islands. In: HALL, C.M. \& WILLIAMS, A.M. (Editors). Tourism and Migration. New Relationships between Production and Consumption. London: Kluwer Academic Publishers, 2002, p. 119-134.

SCHRIEWER, K. y GARCÍA, M. Entre europeos: acerca de una posible conciencia europea. El caso de residentes europeos en España. En: FERNÁNDEZ, J. y GARCÍA, M. (Editores). Movimientos migratorios contemporáneos. Murcia: Universidad Católica San Antonio, 2005, p. 181-204.

SIMÓ, C.; JABBAZ, M.; TORRES, F.; GINER, J. y HERZOG, B. Asociacionismo y población extranjera en la Comunidad Valenciana. Cuadernos Electrónicos de Filosofía del Derecho, 2005, № 12 . Disponible en Internet: http://www.uv.es/CEFD/12/simo.pdf

TREMBLAY, R. \& O'REILLY, K. La mise en tourisme des communautés transnationales: le cas des Britanniques en Espagne et des Québécois en Floride. Tourism Review, 2004, Vol. 59, No 3, p. 20-33. 
